Journal of Electronics and Informatics (2020)

Vol.02/ No. 01

Pages: $38-48$

http://www.irojournals.com/iroei/

DOI: https://doi.org/10.36548/jei.2020.1.005

\title{
Assessment of Fire Risk and Forest Fires in Rural Areas Using Long Range Technology
}

\author{
Dr. S. Smys, \\ Professor, Department of Computer Science and Engineering, \\ RVS Technical Campus, \\ Coimbatore, India. \\ Email: smys375@gmail.com \\ Dr. Jennifer S. Raj, \\ Professor, Department of ECE, \\ Gnanamani College of Technology, \\ Namakkal, India. \\ Email: jennifer.raj@gmail.com
}

\begin{abstract}
The occurrences of forest fires is not only a progressing concern in the lives of the people but also in the deterioration of the environment. Since the emergence of the internet of things, new methodologies are being continuously devised to have an early knowledge about the occurrence of the forest fires. The identifying the areas with the fire risks and the intimating it to the public would minimize the death rate caused due to these types of fire accidents. So the paper utilizes the cost- effective network that is centered on long range technology to automatically assess the degree of fire risky and forest fire rural areas and transmit to the website for public vision using the things network server. The proposed method includes many long range nodes and the sensing element to measure the atmospheric changes and the $\mathrm{CO}_{2}$ level in the environment. The long range based sensor network used in the detection of the fire risky and the forest fire areas is evaluated using the network simulator- 2 and was found to provide an enhanced service quality by providing a better coverage, battery life, latency, cost and as well as efficiency.
\end{abstract}

Keywords: Fire Monitoring, Fire Risky Areas, Long Range Technology, Sensor Networks, Things Network

\section{Introduction}

The hot summers often cause many threats including the forest fires, which result in multitude of materials and individual damages causing insecurity for the lives of the people, animals found in the forest. This further affects the ecosystem due to large emission of $\mathrm{CO}_{2}$. Most of the country's that are widely affected by this forest fire are Europe, North Africa, and Middle East. Though the government of the respective

ISSN: 2582-3825 (online) 
Journal of Electronics and Informatics (2020)

Vol.02/ No. 01

Pages: $38-48$

http://www.irojournals.com/iroei/

DOI: https://doi.org/10.36548/jei.2020.1.005

country has devised a preventive as well as extermination measures, still the forest fires every year causes a considerable amount of losses in the human lives.

The emergence of Internet of things led multitude of researcher's to devise an methodologies to have an early knowledge about the forest fires, this was not much capable in alarming the people, so it was found that it is important to identify the fire risky areas and intimate it to the public, and so the proposed method has utilized the long-range technology shortly termed as Lo-Ra to assess the fire risky areas and the forest fire in the rural areas to intimate the public and enable them to have early insight about the fire accident.

Long Range technology communicates using the wireless medium, to forward the data packets using the transmitter that is designed with the low power capability to the receiver that is located in a longer distance. It covers a broad area, of about $20 \mathrm{~km}$ in the rural areas and $5 \mathrm{~km}$ in the urban areas. It uses a CSS modulation scheme that utilizes the pulses in form chirp to modulate the information. It has high bandwidth. The proposed method utilizes the long range WAN to extend communication and collect the information

The long range WAN is network protocol that supports the applications of low power WAN i.e. the appliances that are powered by batteries but demands a broader coverage with low power utilization. The figure. 1 below presents the network architecture of the Lo-Ra WAN.

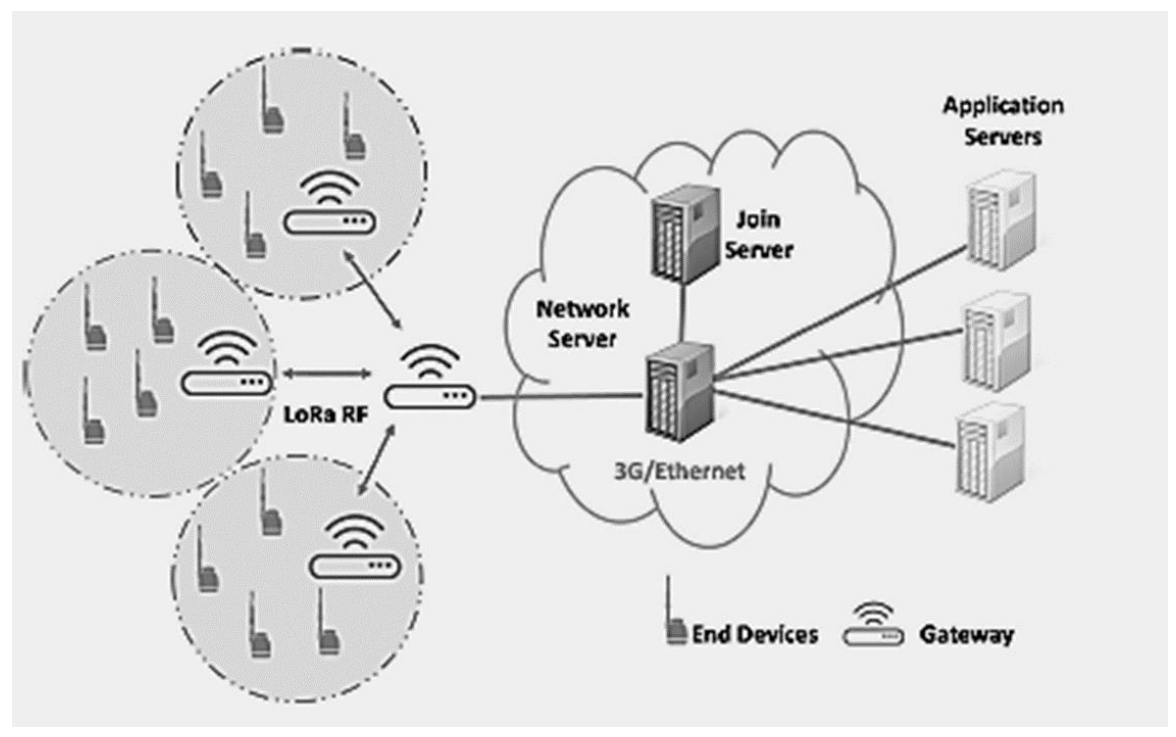

Figure. 1 Network Architecture of Lo-Ra WAN [7]

ISSN: 2582-3825 (online) 
Journal of Electronics and Informatics (2020)

Vol.02/ No. 01

Pages: $38-48$

http://www.irojournals.com/iroei/

DOI: https://doi.org/10.36548/jei.2020.1.005

The figure. 1 shows a star topology based network architecture of Lo-Ra WAN, as depicted in the figure above the information across the devices at the end and the centralized serves is conveyed using the gateways. The server forwards the data packets of every devices to the application server. The information's conveyed are secured using the symmetric keys that are got from the root keys of every devices. "The key associated with the device and the session keys derived from them are stored by the incoming server." The servers that work for the network, application and the as the incoming unit are accommodated by a single machine.

The network server and the gateway are linked using the "traditional TCP/IP SSL" network, and the communication between the gateways and the devices are extended using the Lo-Ra WAN. The gateways gather the information's from different motes and links them with the other devices of the network. The three various flows that can be observed are. (i) The uplink flow, "where the router receives the uplink information from the gateway and parses the uplink content for the MAC payload and activations, and further estimates the new down link windows and identifies a broker to convey the packets to and transmit the uplink. (ii) The downlink flow, "the router receives the down link messages from upstream and waits for a gateway near the device to be available. Finally it builds downlink options from the gateway options and transmits it" and the (iii) the status messages, "the router utilizes the messages to track the active gate ways".

All the above messages are generated and transmitted across the gateway and the things network server using the protocols "gate way connector and the semtech UDP" where the former takes care of the security provision, the latter provides the exchange of the downlink, uplink and the status in the Pseudo-JSON format across the gateways and the servers of the network. So all the communications taking place are bidirectional, however the Lo-Ra WAN does not support the conveyance across the nodes at the end.

The Proposed method utilizes the Lo-Ra WAN in devising system to assess the risky fire areas and the forest fires in the rural areas along with the sensor networks. The remaining part is organized with the literature survey in the part two, the proposed work in part three, the results evaluation in part 4 and the conclusion in part 5

\section{Literature Survey}

G. Josemin Bala et al [1] introduced "Self-organizing hierarchical structure for wireless networks." In the year 2010, Herutomo, et al [2] performed the "Forest fire detection system reliability test using wireless

ISSN: 2582-3825 (online) 
Journal of Electronics and Informatics (2020)

Vol.02/ No. 01

Pages: $38-48$

http://www.irojournals.com/iroei/

DOI: https://doi.org/10.36548/jei.2020.1.005

sensor network and OpenMTC communication platform." Alkhatib et al [3] conducts the "Sub-network coverage method as an efficient method of wireless sensor networks for forest fire detection."

Cantuna et al [4] proposed the "Design and implementation of a Wireless Sensor Network to detect forest fires." Kumar, R et al [5] elaborates the "A novel report on architecture, protocols and applications in Internet of Things (IoT)." Antunes et al [6] provides the "Low-Cost System for Early Detection and Deployment of Countermeasures against Wild Fires." Froiz-Míguez, et al [7] puts forth the "LoRaWAN and Blockchain based Safety and Health Monitoring System for Industry 4.0 Operators."

Mikhaylov, et al [8] devised the "On LoRaWAN scalability: Empirical evaluation of susceptibility to internetwork interference." Raj, Jennifer $\mathrm{S}$ et al [9] proposed the "QoS optimization of energy efficient routing in IoT wireless sensor networks." Pandian, A. Pasumpon et al [10] demonstrated the. "Enhanced Edge Model For Big Data In The Internet Of Things Based Applications." Smys, S et al [11] developed the "Internet of Things and Big Data Analytics for Health Care with Cloud Computing." R. Harikumar et al [12] devised "A new distributed architecture for connectivity analysis in wireless networks."

\section{Proposed Architecture}

The architecture for detecting the fire risky areas and the forest fires, is designed with the end devices utilizing the Lo-Ra Class, the gateways take the responsibility of collecting the data from the motes. The collected data are directed to the server from the nodes of the Lo-Ra, in order to compute and store. The information's gathered are usually stored in the network server for storage. But as the proposed design uses the things network, that provides the cost effective way and the tools essential in gathering and saving the information in the database. The things network server sends the information to the website to envisage the information's from the sensors and estimate the areas that are risky and likely to get affected by the forest fire. The Block Diagram in figure. 2 below explains the process.

The nodes components as depicted in figure. 2 holds the sensors responsible for gathering the data from the environment, now the verge for the risk level is set above 40 degree Celsius for the temperature, approximately 40 for the humidity level and 30 for the wind speed whenever the temperature is equal to or beyond 40 degree Celsius and if the humidity in the air goes below 40 percentage as well as the wind speed is above thirty $\mathrm{Km} / \mathrm{H}$, and the precipitation is absent, immediately a warning thee area is depicted as the fire risky area through the web application.

ISSN: 2582-3825 (online) 
Journal of Electronics and Informatics (2020)

Vol.02/ No. 01

Pages: $38-48$

http://www.irojournals.com/iroei/

DOI: https://doi.org/10.36548/jei.2020.1.005

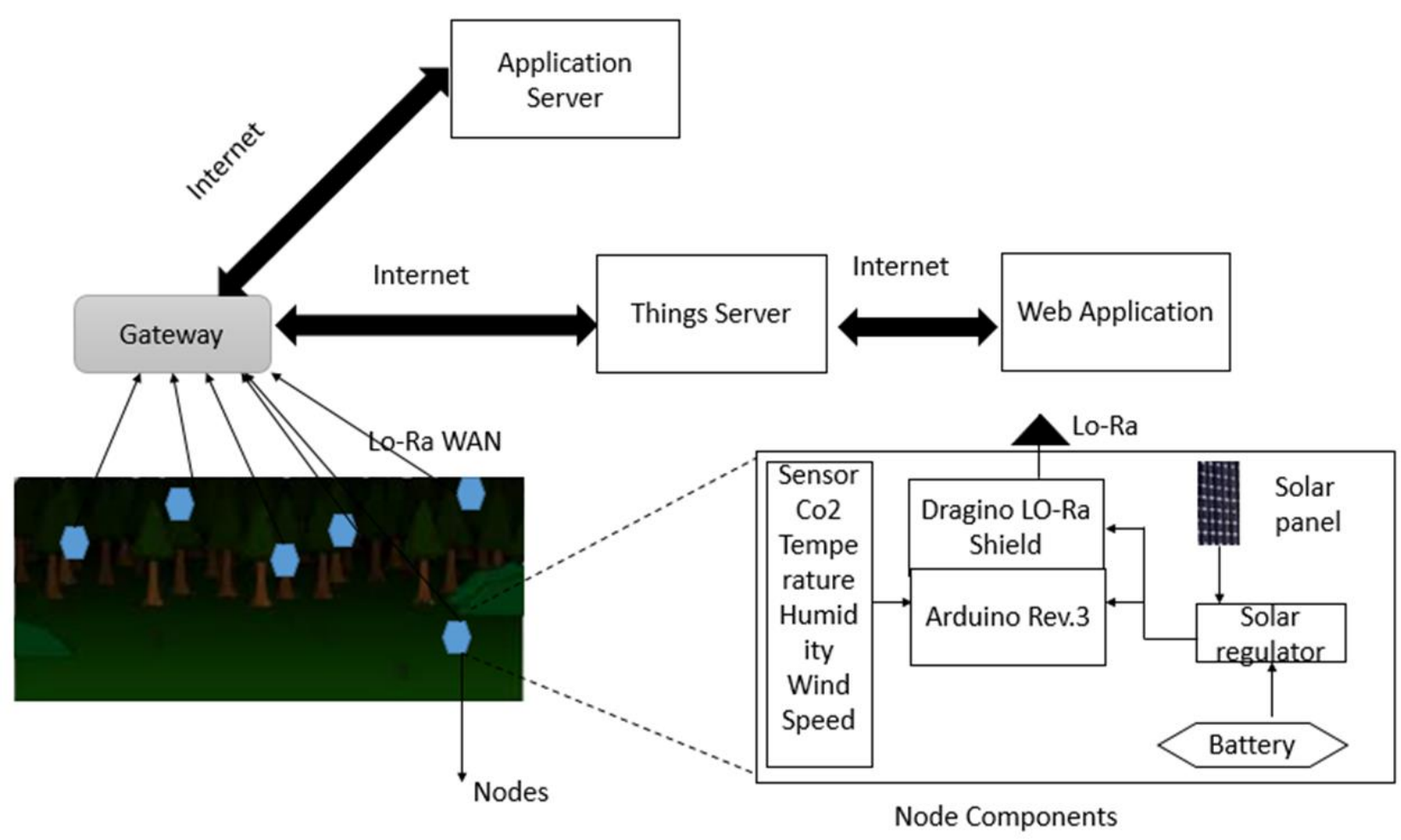

Figure. 2 Proposed Architecture

As shown figure. 2 an Arduino Rev.3 with ATmeaga32p microcontroller is present inside the node component, this is connected to the Lo-Ra using the Dragino Shield, the Shield board is encompassed with a transceiver (RFM95W) and Semtech (SX1276) Chip to help in modulation process under frequencies, 433.01MHz, 915.01MHz and 868.01 MHz. The wasp mote sensors comprised of DHT11, MQ135, for measuring the temperature, humidity, and $\mathrm{CO}_{2}$ respectively, and uses DC motor as generator for measuring the speed of the wind.

On developing the application the registration of the nodes are done to be identified as device, further the identifiers and the eight bytes Device EUI is allocated. The KEY for Application is generated by the Things network automatically and allotted to the Application EUI. Once the devices are activated the session key is provided and the address of the device is noted down in the source code of every node. The information's are either found in the numerical or the hexadecimal format. Followed by the activation of the devices the data base installation is done, the information gathered are stored in JSON format in the database,

ISSN: 2582-3825 (online) 
Journal of Electronics and Informatics (2020)

Vol.02/ No. 01

Pages: $38-48$

http://www.irojournals.com/iroei/

DOI: https://doi.org/10.36548/jei.2020.1.005

The HTTP application server initiates the requisition to the storage that is present is in the things network server. The data in the server is transformed to an understandable format, for this purpose a transcriber is utilized in the Web-Server to simultaneously transform the information's gathered into readable form. The programming is done using the Python to perform three fundamental operations. Such as requesting the storage of the things network, converting the information's gathered to an understandable format. The timestamp for the every information gathered is also noted down. For phrasebook for the device coordinates and the argument embedded in the format of JSON is used in the application interface of the Web. The phrase book used saves the values of the preceding co-ordinates and detects the nodes that generated the data and reserves the values of coordinates to the phrase book. The information's are finally reserved in the JSON format with extension .json. The file is developed to indicate the co-ordinates values that exceed beyond the verge level set. The values are received from the data file created in JSON format and a marker is set to indicate the risk level by sending alert information over the screen. The web server used in the method was developed by implementing the programing created in JAVA script.

\section{Result Analysis}

The system proposed is designed using the python and Java script and is simulated in network simulator II to evince the Lo-Ra's latency, power consumption, cost coverage etc. The displayed table.1 below shows the necessary parameters that are employed in the simulation process. Further the results obtained are compared with the other technologies such as the Wi-Fi, Zigbee, SigFox, and NB-IoT

\begin{tabular}{|l|l|}
\hline \multicolumn{1}{|c|}{ Parameters } & \multicolumn{1}{c|}{ Values } \\
\hline Channels & 10 \\
\hline Working Frequency & $433.01 \mathrm{MHz}, 915.01 \mathrm{MHz}$ and $868.01 \mathrm{MHz}$ \\
\hline Wireless Connectivity & Lo-Ra, Internet \\
\hline Power & USB-C adapter with 1000 milli Amps \\
\hline Antenna & Bidirectional \\
\hline Radio Module & Semtech and gate connector protocols \\
\hline Power Requirement of sensors & 2 milli Ah \\
\hline Power Required for Lo-Ra & $0.0140 \mathrm{mAh}$ \\
\hline Total transmission power & $1.799 \mathrm{mAh}$ \\
\hline Battery capacity & $20,000 \mathrm{mAh}$ \\
\hline
\end{tabular}

Table.1 Simulation Parameters

ISSN: 2582-3825 (online) 
Journal of Electronics and Informatics (2020)

Vol.02/ No. 01

Pages: $38-48$

http://www.irojournals.com/iroei/

DOI: https://doi.org/10.36548/jei.2020.1.005

The results below in the figure. 3 shows the percentage of latency observed in every wireless technologies, based on the evaluation compared to Wi-Fi, Zigbee, SigFox, and NB-IoT, the Lo-Ra provided fastest transmission reducing the delay incurred in the network.

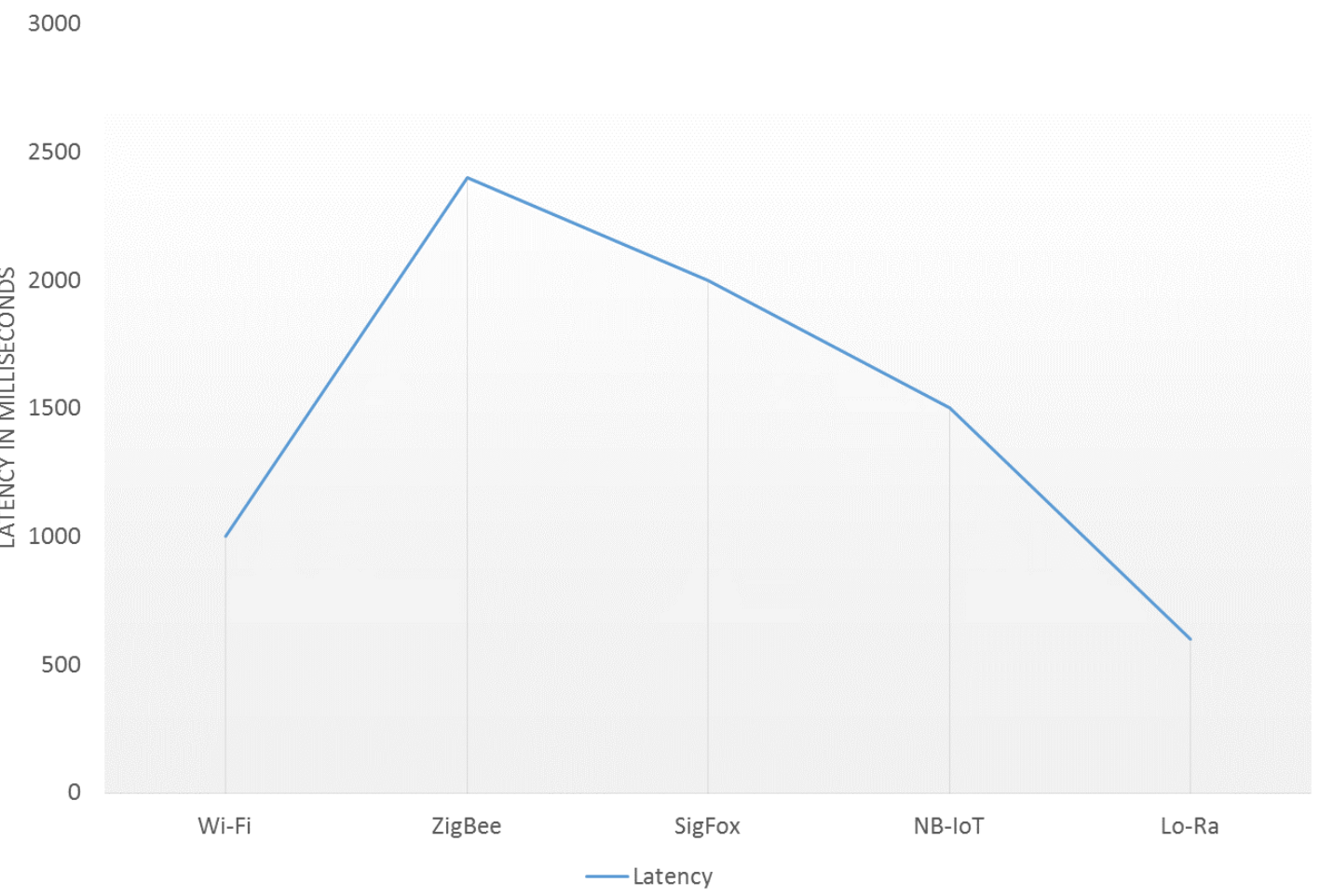

Figure.3 Latency Observed

The figure. 4 shows the evaluation results on the power consumed by each wireless communication technologies, the power consumed by Lo-Ra, SigFox and NB-Iot were considerable lower compared to the Wi-Fi and the ZigBee among the Lo-Ra, SigFox and NB-Iot the Lo-Ra Proved have a less power consumption as it utilized the low power components that were supported by the battery.

ISSN: 2582-3825 (online) 
Journal of Electronics and Informatics (2020)

Vol.02/ No. 01

Pages: $38-48$

http://www.irojournals.com/iroei/

DOI: https://doi.org/10.36548/jei.2020.1.005

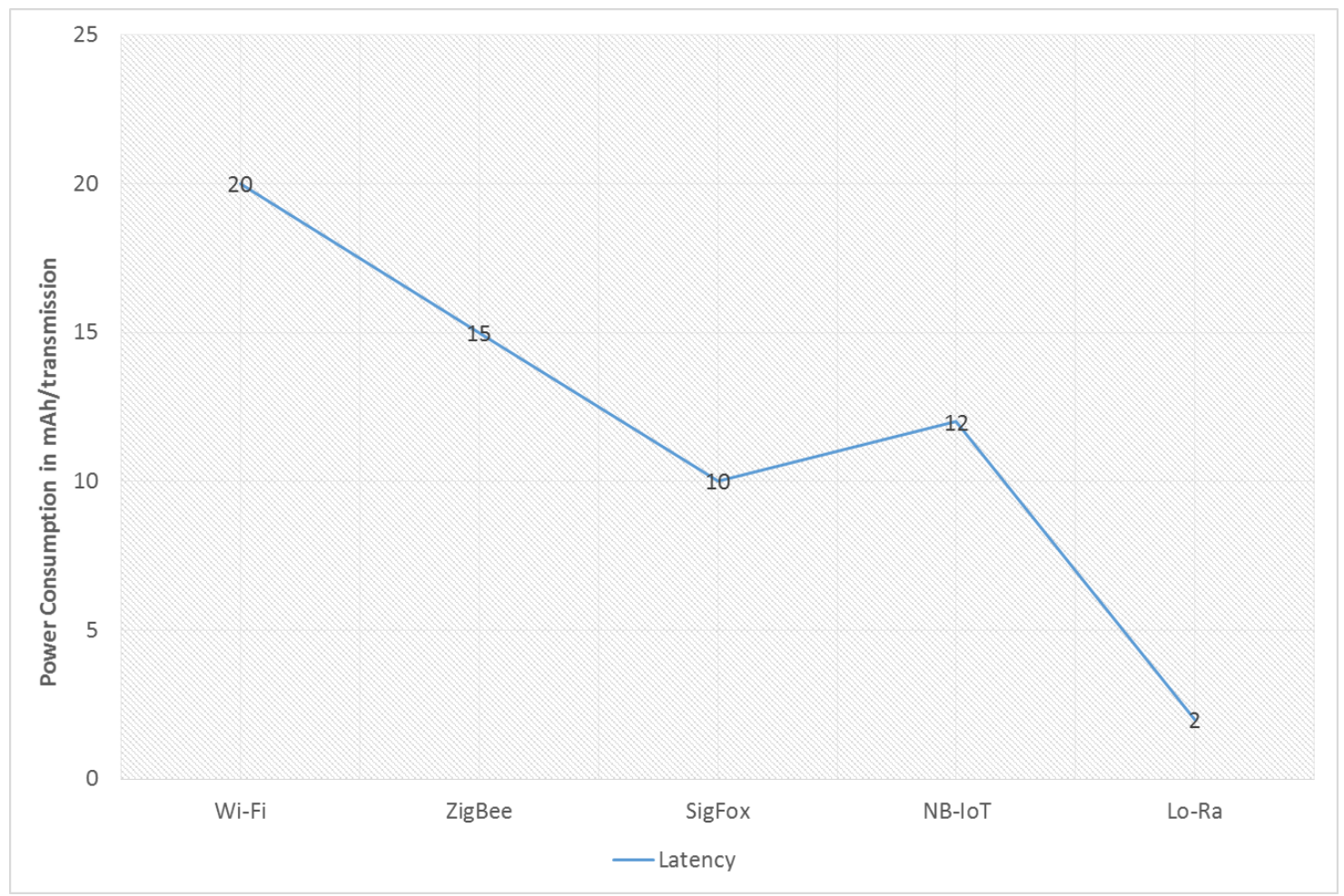

Figure.4 Power Consumption.

The Table 2 below shows the comparison of the various wireless communication technologies employed in IOT. Presenting the theoretical data transfer rate long with its frequency, standard and coverage range.

ISSN: 2582-3825 (online) 
Journal of Electronics and Informatics (2020)

Vol.02/ No. 01

Pages: $38-48$

http://www.irojournals.com/iroei/

DOI: https://doi.org/10.36548/jei.2020.1.005

\begin{tabular}{|c|c|c|c|c|}
\hline Technologies & Frequency & Standard & Coverage & $\begin{array}{l}\text { Theoretical } \\
\text { Data Transfer } \\
\text { Rate }\end{array}$ \\
\hline Wi-Fi & $\begin{array}{l}2.4 \mathrm{GHz} \text { and } 5 \\
\mathrm{GHz}\end{array}$ & IEEE802.11 & $\begin{array}{l}50 \mathrm{~m} \text { (indoor), } \\
40 \mathrm{~km} \text { (outdoor, } \\
\text { as a function of } \\
\text { the visibility) }\end{array}$ & $\begin{array}{l}2.4 \text { Gbps } \\
\text { (IEEE } 802.11 \text { ax, } \\
2 \text { streams with } \\
1024 \text { QAM }\end{array}$ \\
\hline ZigBee & $\begin{array}{l}868 \mathrm{MHz} \text { (EU); } \\
915 \mathrm{MHz} \\
\text { (USA); } 433 \\
\mathrm{MHz} \text { (Asia); } 2.4 \\
\mathrm{GHz}\end{array}$ & IEEE802.15.4 & $10-100 \mathrm{~m}$ & $\begin{array}{l}250 \mathrm{kbps} \text { at } 2.4 \\
\mathrm{GHz}, 20 \mathrm{kbps} \text { at } \\
868 \mathrm{MHz}, 40 \\
\mathrm{kbps} \text { at } 915 \\
\mathrm{MHz}\end{array}$ \\
\hline SigFox & $\begin{array}{l}868 \mathrm{MHz}(\mathrm{EU}) \\
915 \mathrm{MHz} \\
\text { (USA), } 433 \\
\text { MHz (Asia) }\end{array}$ & SigFox (Owner) & $\begin{array}{l}10 \mathrm{~km} \text { (urban), } \\
40 \mathrm{~km} \text { (rural) }\end{array}$ & $100 \mathrm{bps}$ \\
\hline NB-IoT & $\begin{array}{l}\text { Depends on the } \\
\text { frequency } \\
\text { licensed to LTE }\end{array}$ & 3GPP Standard & $\begin{array}{l}1 \mathrm{~km} \text { (urban), } \\
10 \mathrm{~km} \text { (nural) }\end{array}$ & $10 \mathrm{Mbps}$ \\
\hline Lo-Ra & $\begin{array}{l}\text { 433.01MHz, } \\
915.01 \mathrm{MHz} \text { and } \\
868.01 \mathrm{MHz}\end{array}$ & $\begin{array}{l}\text { IEEE } 802.15 .4 \mathrm{~g}, \\
\text { LoRa Alliance }\end{array}$ & $\begin{array}{l}5 \mathrm{~km} \text { (urban), } 20 \\
\mathrm{~km} \text { (rural) }\end{array}$ & $\begin{array}{l}22 \mathrm{kbps} \text { (LoRa), } \\
100 \mathrm{kbps} \\
\text { (GFSK) }\end{array}$ \\
\hline
\end{tabular}

Table.2 Comparison of Wireless communication Technologies

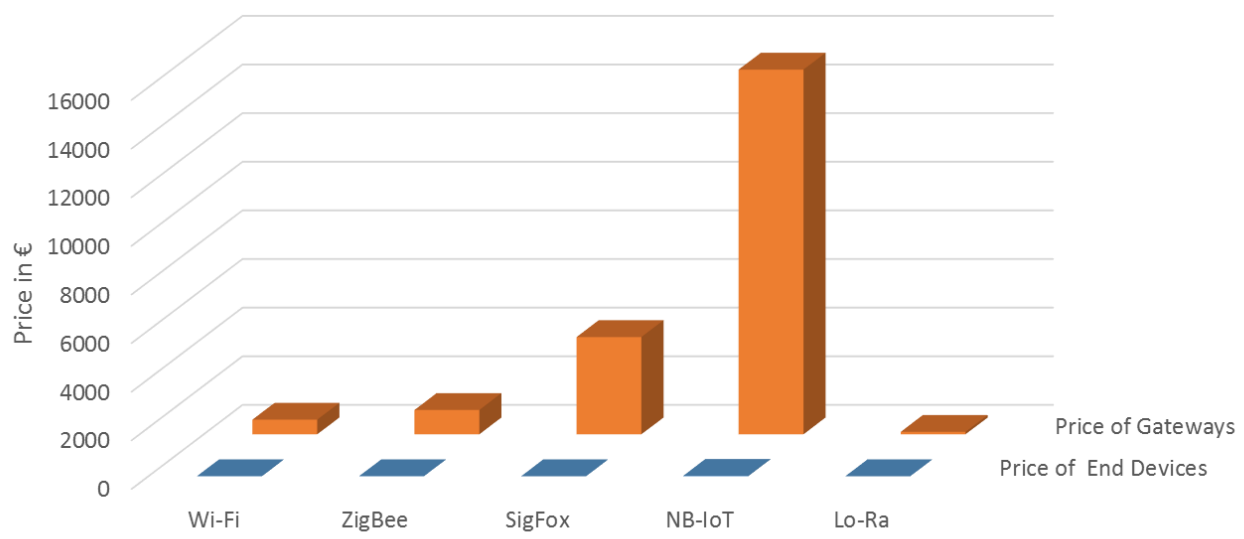

- Price of End Devices $\quad$ Price of Gateways

Figure. 5 Price Chart

ISSN: 2582-3825 (online) 
Journal of Electronics and Informatics (2020)

Vol.02/ No. 01

Pages: $38-48$

http://www.irojournals.com/iroei/

DOI: https://doi.org/10.36548/jei.2020.1.005

The Figure. 5 Shows the price chart of the end devices and the gateway or the base station used in the wireless communication technologies, the price of the Lo-Ra are comparatively low when compared to the other technologies such as Wi-Fi, SigFox, ZigBee, Etc.

\section{Conclusion}

In order to develop am assessment device for identifying the fire risky and the forest fire in the rural areas the proposed method devised the system utilizing the wireless sensor network empowered by the long range technology that uses low power transceiver and the battery powered devices as its end components, to have an early initiation of the fire accidents and to safe guard the people. The proposed model conveyed the information's to the things network server to make it available in the web interface to bring it to the knowledge of humans. The complete set up was developed using the python and the Java script. The LoRa used in the proposed system was evaluated using the network simulator- 2 to evince its competencies against the other wireless communication technologies that are prevailing. The results observed proved that Lo-Ra offered better service quality in terms of coverage, latency, power Consumption, cost etc. compared to the other expertise such as Wi-Fi, Zigbee, SigFox, and NB-IoT.

\section{References}

[1] Smys, S., G. Josemin Bala, and Jennifer S. Raj. "Self-organizing hierarchical structure for wireless networks." In 2010 international conference on advances in computer engineering, pp. 268-270. IEEE, 2010.

[2] Herutomo, Anton, Maman Abdurohman, Novian Anggis Suwastika, Sidik Prabowo, and Catur Wirawan Wijiutomo. "Forest fire detection system reliability test using wireless sensor network and OpenMTC communication platform." In 20153 rd International conference on information and communication technology (ICoICT), pp. 87-91. IEEE, 2015.

[3] Alkhatib, Ahmad. "Sub-network coverage method as an efficient method of wireless sensor networks for forest fire detection." In Proceedings of the International Conference on Internet of things and Cloud Computing, pp. 1-7. 2016.

[4] Cantuna, Jorge Granda, Dennis Bastidas, Santiago Solórzano, and Jean-Michel Clairand. "Design and implementation of a Wireless Sensor Network to detect forest fires." In 2017 Fourth international conference on eDemocracy \& eGovernment (ICEDEG), pp. 15-21. IEEE, 2017.

[5] Kumar, R. Praveen, and S. Smys. "A novel report on architecture, protocols and applications in Internet of Things (IoT)." In 2018 2nd International Conference on Inventive Systems and control (ICISC), pp. 1156-1161. IEEE, 2018.

ISSN: 2582-3825 (online) 
Journal of Electronics and Informatics (2020)

Vol.02/ No. 01

Pages: $38-48$

http://www.irojournals.com/iroei/

DOI: https://doi.org/10.36548/jei.2020.1.005

[6] Antunes, Miguel, Luís Miguel Ferreira, Carlos Viegas, A. Paulo Coimbra, and Aníbal T. de Almeida. "Low-Cost System for Early Detection and Deployment of Countermeasures Against Wild Fires." In 2019 IEEE 5th World Forum on Internet of Things (WF-IoT), pp. 418-423. IEEE, 2019.

[7] Froiz-Míguez, Iván, Paula Fraga-Lamas, José Varela-Barbeito, and Tiago M. FernándezCaramés. "LoRaWAN and Blockchain based Safety and Health Monitoring System for Industry 4.0 Operators." In Presented at the 6th International Electronic Conference on Sensors and Applications, vol. 15, p. 30. 2019.

[8] Mikhaylov, Konstantin, Juha Petäjäjärvi, and Janne Janhunen. "On LoRaWAN scalability: Empirical evaluation of susceptibility to inter-network interference." In 2017 European Conference on Networks and Communications (EuCNC), pp. 1-6. IEEE, 2017.

[9] Raj, Jennifer S. "QoS optimization of energy efficient routing in IoT wireless sensor networks." Journal of ISMAC 1, no. 01 (2019): 12-23.

[10] Pandian, A. Pasumpon. "Enhanced Edge Model For Big Data In The Internet Of Things Based Applications." Journal of trends in Computer Science and Smart technology (TCSST) 1, no. 01 (2019): 63-73.

[11] Smys, S., and Jennifer S. Raj. "Internet of Things and Big Data Analytics for Health Care with Cloud Computing." Journal of Information Technology 1, no. 01 (2019): 9-18.

[12] Raj, Jennifer S., and R. Harikumar. "A new distributed architecture for connectivity analysis in wireless networks." Procedia Engineering 30 (2012): 394-401.

ISSN: 2582-3825 (online) 